\title{
Removal of Nickel(II) from Aqueous Solution by Complexation- Ultrafiltration with Polyvinyl Pyrrolidone
}

\author{
Zhixin Chen ${ }^{\mathrm{a}}$, Jianxian Zeng ${ }^{\mathrm{a},{ }^{*}}$ and Yangen Ding ${ }^{\mathrm{b}}$ \\ ${ }^{a}$ College of Chemistry and Chemical Engineering, Hunan University of Science and Technology, Xiangtan \\ 411201, P R. China \\ ${ }^{b}$ Xiangtan Electrochemical Scientific, Ltd., Xiangtan 411202, P R. China
}

\begin{abstract}
This study confers insight into the removal of Nickel(II) from aqueous solution by complexation-ultrafiltration (CP-UF) technique with water-soluble polymer polyvinyl pyrrolidone (PVP). The whole experiment process includes five parts: pre-treatment, CP-UF, concentration, decomplexation and regeneration of polymer. Numerous factors affecting the retention rate of Nickel(II) $\left(R_{\mathrm{Ni}}\right)$ and permeate flux $(\mathrm{J})$, such as $\mathrm{pH}$, loading ratio, transmembrane pressure (TMP), complexation time and added salt have been investigated. In the CP-UF process, $R_{\mathrm{Ni}}$ reaches nearly $94 \%$ while pH of 7 , loading ratio of 4 , TMP of 1.0 bar, temperature of $25^{\circ} \mathrm{C}$, complexation time of 30 min are chosen to be the optimal parameters. In the process of concentration, $J$ declines slowly and $R_{\mathrm{Ni}}$ is very high at loading ratio of 4 and $\mathrm{pH}$ of 7 . Nickel ion concentration in the retentate solution increases linearly with volume concentration factor. In the process of decomplexation, the decomplexation percentage of nickel(II)-PVP complex reaches $42 \%$. The binding capacity of the regenerated PVP is close to that of fresh PVP, and the recovery percentage of binding capacity is higher than $90 \%$.
\end{abstract}

Keywords: Nickel(II), Polyvinyl pyrrolidone, Complexation, Ultrafiltration.

\section{INTRODUCTION}

Nowadays, water pollution has been drawing high concern, especially poisonous heavy metal ions present in industry discharge systems which causes more and more severe environmental issue and negative impact on human health. Therefore, the toxic heavy metals in the wastewater must be removed before discharged into nature water. Wastewaters containing heavy metal ions are produced by several sources like metal finishing, electroplating, electronics, hazardous waste disposal sites and galvanic industries, etc. Conventional treatment processes like chemical precipitation, ion exchange, adsorption, coagulation and flocculation, flotation and electrochemical removal have significant disadvantages like incomplete removal, high-energy requirements, and production of toxic sludge [1]. Recently, complexation-ultrafiltration (CP-UF) technology has been shown to be a promising method for heavy metal ion recovery from aqueous solutions [2-4]. CP-UF process uses the selectivity of a complexation agent (a water soluble macromolecular polymer) along with filtration ability of UF membrane to retain metal-polymer complexes of macromolecular size greater than its molecular weight cut-off (MWCO) [5]. Water-soluble polymeric ligands have shown to be efficient substances to remove heavy metals from aqueous solutions and industrial wastewater through ultrafitration processes [6].

*Address correspondence to this author at the College of Chemistry and Chemical Engineering, Hunan University of Science and Technology, Xiangtan 411201, P R. China; Tel: +86-731-58290045; Fax: +86-731-58290509;

E-mail: zengjianxian@163.com
Nickel is one of the most important transition metals, and its high-purity products are vital for developing advanced materials. Most Nickel is used for the production of stainless steel, non-ferrous alloys and $\mathrm{Ni}$-based superalloys with high corrosion and temperature resistance properties [7]. But the extensive utilization of nickel-containing products sometimes leads to environmental pollution by nickel and its byproducts [8]. Nickel(II) is a kind of non-biodegradable toxic heavy metal ion present in wastewater. In order to protect the environment and human health, the maximum level of Nickel(II) discharged is $1 \mathrm{mg} / \mathrm{L}$ which is established by the Environmental Protection Agency of China. So the recycling of nickel is an attractive option as it provides a means to recover and reuse the metal values and, at the same time, avoid environmental risks.

Heavy metal removal depends on complexation of metal ions by polymer and the complexation depends on some parameters like $\mathrm{pH}$ of feed solution, loading ratio (L), TMP, complexation time, concentration of the added salt. This study will mainly be focused on investigating the applicability of the complexationultrafiltration process for removal of nickel ions from synthetic wastewater solutions.

\section{EXPERIMENTAL}

\subsection{Materials}

Anionic polyvinyl pyrrolidone (PVP) with average molecular mass 40000 provided by Shanhai Gobekie 
Table 1: Specification of Ceramic Ultrafiltration Membrane

\begin{tabular}{|c|c|c|c|c|c|}
\hline Material & MWCO $(\mathbf{k D a})$ & Effective filtration area $\left(\mathbf{m}^{2}\right)$ & Channel diameter $(\mathbf{m m})$ & Channel numbers & Length $(\mathbf{m m})$ \\
\hline \hline Aluminum oxide & 10 & 0.03 & 2.27 & 7 & 600 \\
\hline
\end{tabular}

Company (China) was used as a water-soluble polymeric ligand. Its structural formula is<smiles></smiles>

Hexahydrate nickel sulfate, sodium hydroxide, hydrochloric acid, dimethylglyoxime, anhydrous ethanol and sodium chloride were all purchased from Aladdin Reagent Co., Ltd., as analytical reagent grade. Every solutions were prepared with deionized water of conductivity less than $1 \mu \mathrm{S} / \mathrm{cm}$.

Ceramic ultrafiltration membrane with the molecular weight cut-off of $10000 \mathrm{Da}$ and an effective filtration area of $0.03 \mathrm{~m}^{2}$ was used. It were offered by Shanghai Laungy Technology Co., Ltd. (China). The specification of the ceramic ultrafiltration membrane is given in Table 1.

\subsection{Experimental Procedures}

\subsubsection{Pre-Treatment of Polymer}

The PVP solutions were pretreated in a diafiltration process in the experimental apparatus in order to eliminate the shorter macromolecules that can go through the membrane. The deionized water was added to the reservoir in batches, and permeate streams were sent to a separate tank. The pretreatment was ended until PVP concentrations in the permeate streams decreased to zero [9, 10]. The concentration of the resulting polymer solution was measured with UV-Vis spectrophotometer, and the pretreated PVP solution was used in all complexationultrafiltration experiments.

\subsubsection{CP-UF Process}

Complexation-ultrafiltration (CP-UF) is a developing hybrid process for the removal of heavy metals which uses the selectivity of complexing agent and filtration ability of ultrafiltration membrane [5]. As shown in Figure 1, the ultrafiltration system consists of a thermostatic water bath, a feed tank, a feed diaphragm pump for the flow, two pressure meters, a ceramic ultrafiltration membrane module, a temperature meter, a flow meter and three control valves which enabled optimal running conditions. A $\mathrm{pH}$ meter was used to detect $\mathrm{pH}$ value.

\subsubsection{Concentration, Decomplexation and Reuse of Regenerated Polymer}

The concentration experiment was performed at $\mathrm{pH}$ 7 and loading ratio 4 . Permeate stream was sent to a separate tank, and this experiment was ended when the volume concentration factor (VCF, defined as the ratio between the volume of feed solution and the volume of retentate) reached to 10 . Whereafter, it took full use of the concentrated retentate to complete the

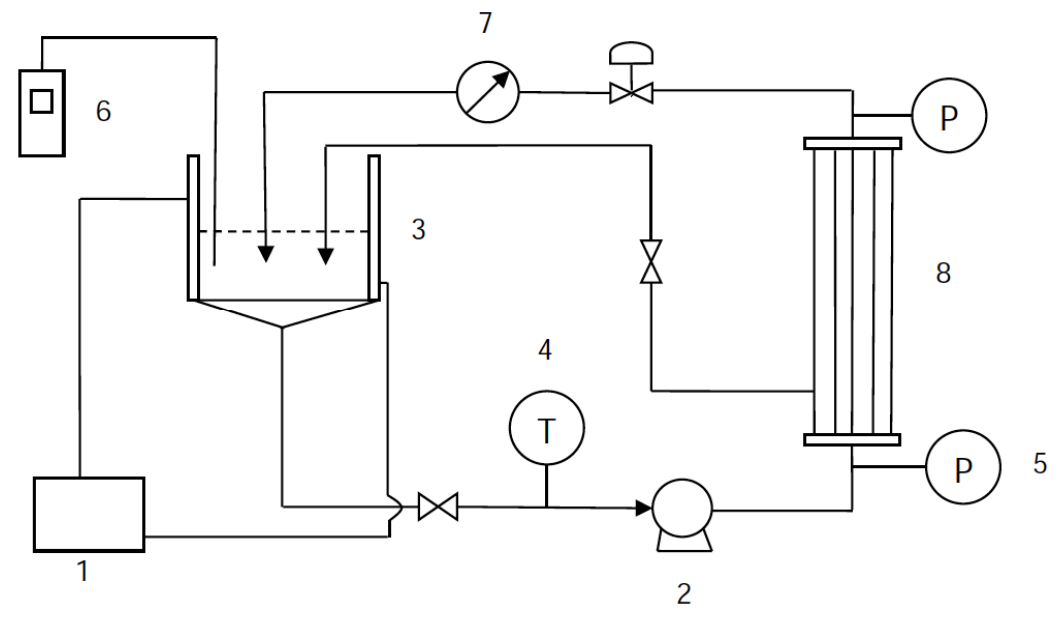

Figure 1: Schematic diagram of ultrafiltration system. (1) thermostatic water bath, (2) pump, (3) feed tank, (4) temperature meter, (5) pressure meter, (6) $\mathrm{pH}$ meter, (7) flow meter, (8) ceramic ultrafiltration membrane module. 
decomplexation process. The decomplexation experiment was performed at $\mathrm{pH} 3$ in total recirculation mode. Polymer reuse experiments were carried out using the regenerated PVP, and compared with the fresh PVP [10].

\section{RESULTS AND DISCUSSION}

The observed retention rate $(R)$, which measures the separation capability of membrane, is given by Eq. (1):

$$
R=\left(1-\frac{C_{\mathrm{p}}}{C_{0}}\right) \times 100 \%
$$

where $C_{\mathrm{p}}(\mathrm{g} / \mathrm{L})$ is metal ion concentration in permeate solution and $C_{0}$ is initial metal ion concentration in feed solution.

Loading ratio $(\mathrm{L})$ is calculated as $\mathrm{Eq}$. (2) to indicate the concentration ratio of polymer $\left(C_{\text {polymer }}\right)$ to metal ion $\left(C_{\text {Metal }}\right)$.

$L=\frac{C_{\text {polymer }}}{C_{\text {Metal }}}$

In Eq. (3), $J$ is the permeate flux $\left(\mathrm{L} \mathrm{h}^{-1} \mathrm{~m}^{-2}\right), V$ denotes the permeate volume collected within time $(t)$ per hour $(h)$ and $A$ is the effective membrane surface area [11].

$J=\frac{V}{A t}$

The volume concentration factor (VCF) is calculated by using Eq. (4):

$$
V C F=\frac{V_{\mathrm{f}}}{V_{\mathrm{f}}-V_{\mathrm{p}}}
$$

Where $V_{f}$ and $V_{p}$ are the volumes of the feed and the total permeate, respectively.

\subsection{Ultrafiltration of PVP Solutions}

Figure 2 shows the effect of the operating time on instantaneous permeate flux $\left(J_{i}\right)$ under different transmembrane pressure (TMP). The studied $\mathrm{pH}$ was 7 and temperature was $25^{\circ} \mathrm{C}$. As it is clear, $J_{i}$ decreases slightly as the time varies from $5 \mathrm{~min}$ to $50 \mathrm{~min}$, while it tends to keep stable after $50 \mathrm{~min}$ under different transmembrane pressure. $J_{i}$ increases with increasing TMP, which can be explained by the Forshcheimer equation.

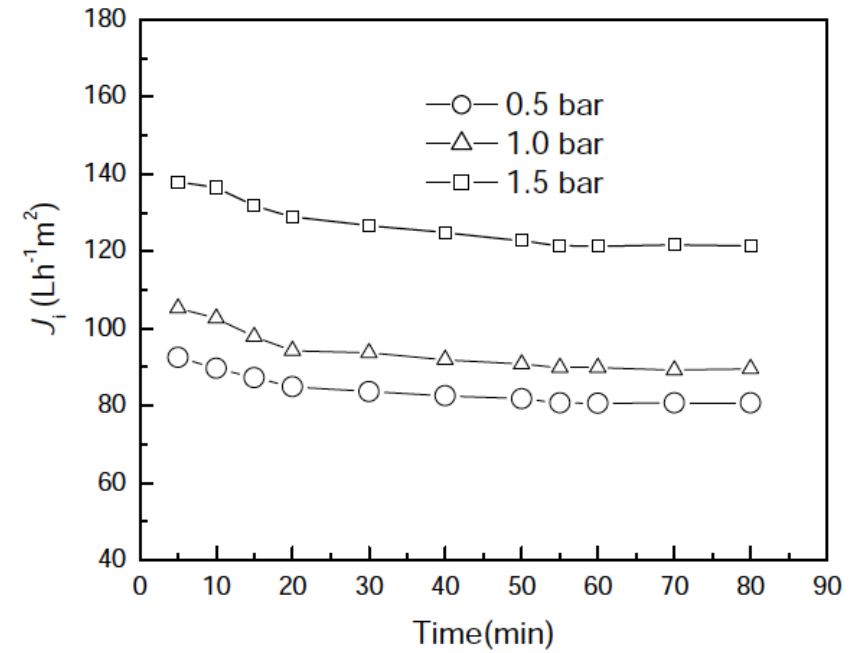

Figure 2: Effect of operating time on instantaneous permeate flux under different transmembrane pressures $(\mathrm{pH}, 7$; temperature, $25^{\circ} \mathrm{C}$; initial PVP concentration, $\left.106 \mathrm{mg} / \mathrm{L}\right)$.

The effect of transmembrane pressure on retention rate of PVP $\left(R_{\mathrm{p}}\right)$ has been shown in Figure 3 . When the TMP increases from 0.5 bar to 1.5 bar, $R_{\mathrm{p}}$ value changes insignificantly. It might be due to the mechanism that the TMP only changes the pressure on both sides of the membrane, just accelerates the permeate rate, and it hardly changes molecule structure of PVP or membrane's pore size, thus it does not affect retention rate.

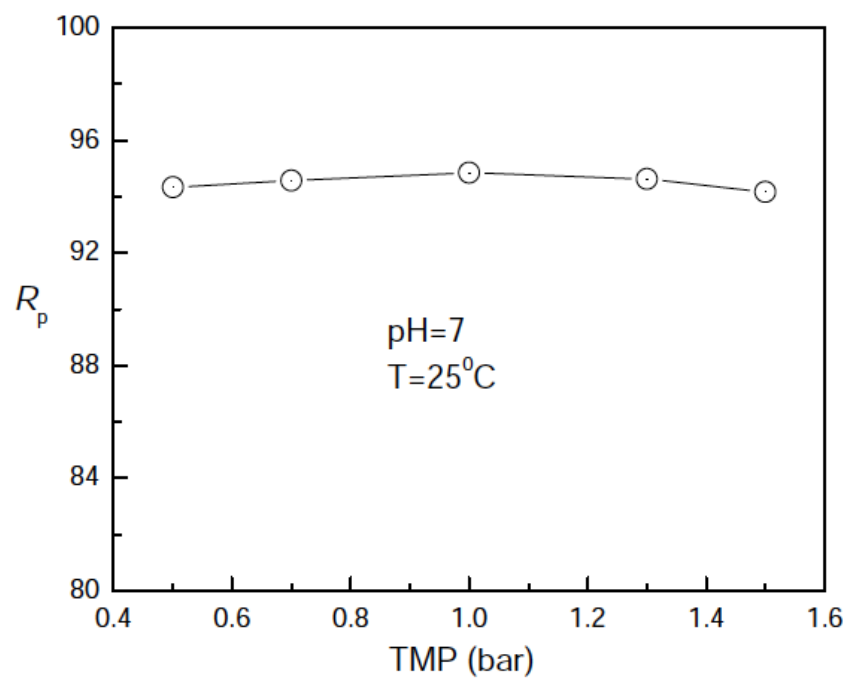

Figure 3: The effect of transmembrane pressur on retention rate of PVP $\left(\mathrm{pH}, 7\right.$; temperature, $25^{\circ} \mathrm{C}$; initial PVP concentration, $106 \mathrm{mg} / \mathrm{L})$.

Figure 4 shows that steady permeate flux $\left(J_{s}\right)$ are not influenced by $\mathrm{pH}$. The phenomenon may be explained as: a change of the conformation of PVP molecule does not occur and membrane fouling does not change with $\mathrm{pH}$. 


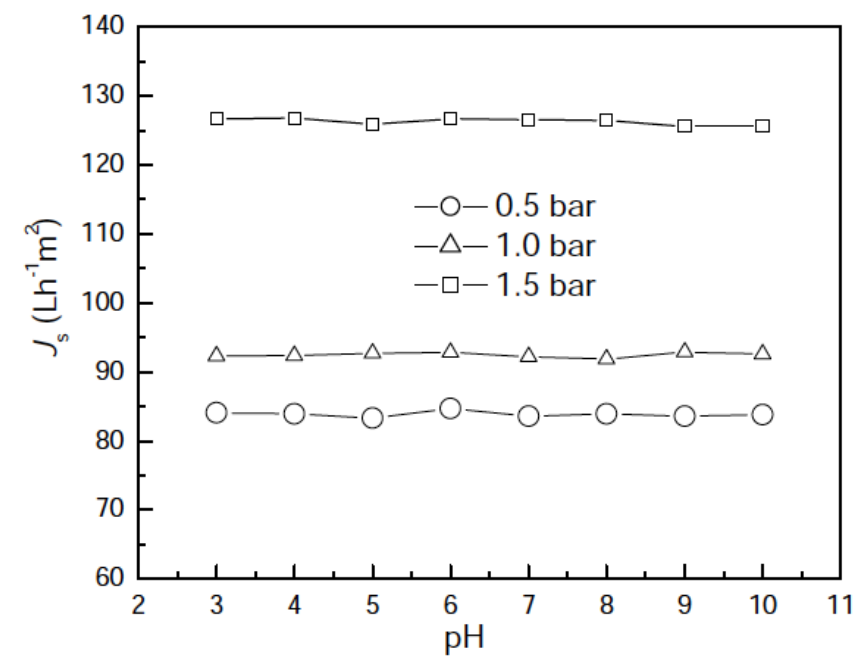

Figure 4: Effect of $\mathrm{pH}$ on steady permeate flux under different transmembrane pressures (temperature, $25^{\circ} \mathrm{C}$; initial PVP concentration, $106 \mathrm{mg} / \mathrm{L})$.

The effect of $\mathrm{pH}$ on $R_{\mathrm{p}}$ under different transmembrane pressure has been illustrated in Figure 5. The retention rate obtained in the $\mathrm{pH}$ range 310 are almost equal. This means that $R_{\mathrm{p}}$ is not influenced by $\mathrm{pH}$. This may be attributed to the stability of the PVP molecular structure which is $\mathrm{pH}$ independent.

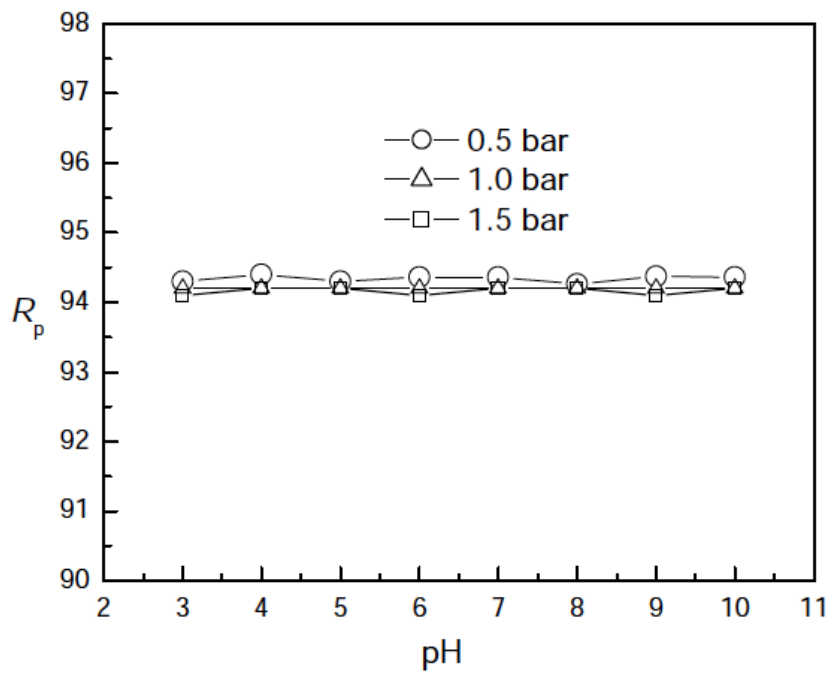

Figure 5: Effect of $\mathrm{pH}$ on retention rate under different transmembrane pressures (temperature, $25^{\circ} \mathrm{C}$; initial PVP concentration, $106 \mathrm{mg} / \mathrm{L})$.

\subsection{Fourier Transform Infrared Spectoscopy Study}

The FT-IR spectra of PVP(a) and PVP-Ni(b) are depicted in Figure 6. As shown in lines $a$ and $b$, the intensity of the broad band between 3600 and 3100 $\mathrm{cm}^{-1}$, which is attributable to the $-\mathrm{OH}$ stretching vibrations of water. The stretching vibrations of methyl $\left(-\mathrm{CH}_{3}\right)$ and methylene $\left(-\mathrm{CH}_{2}-\right)$ groups are observed in the region 2950 to $2800 \mathrm{~cm}^{-1}$. The stretching vibration of $\mathrm{C}=\mathrm{O}$ bond is observed at $1674 \mathrm{~cm}^{-1}$ in line a, but it has weaken in lin $\mathrm{b}$. The deformation vibration of $\mathrm{C}-\mathrm{N}$ is found at $1098 \mathrm{~cm}^{-1}$ in line a, but it shifts to $1026 \mathrm{~cm}^{-1}$ in line b. Negatively charged nitrogen ions exist in the anionic polyvinyl pyrrolidone which may have coordination effect or electrostatic forces to bond with positive charge of nickel (II) ion. Comprehensive analysis indicates that nickel ions have been bound to the PVP.

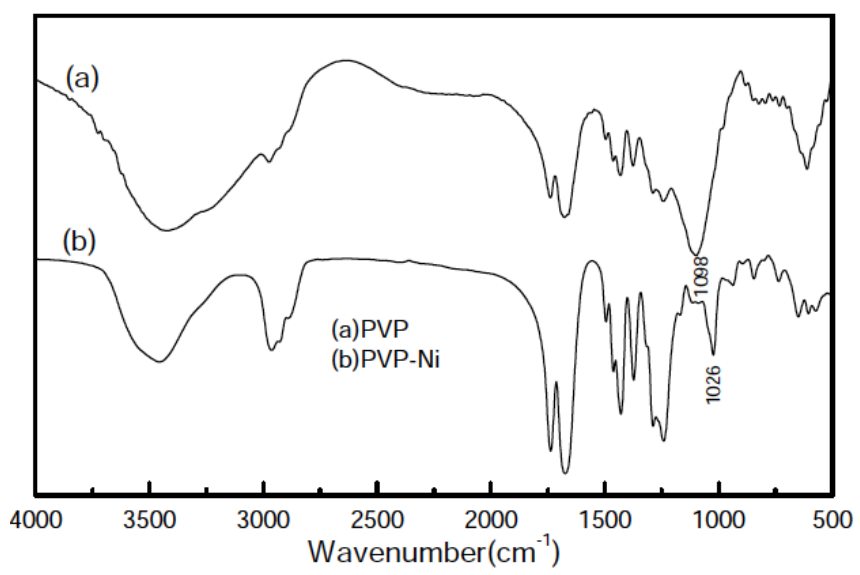

Figure 6: FTIR spectra of PVP(a) and PVP-Ni(b).

\subsection{Effect of Operating Parameters on Nickel Removal}

\subsubsection{Effect of Complexation Time on Nickel Removal}

Figure 7 shows the variations of retention rate of nickel ions $\left(R_{\mathrm{Ni}}\right)$ and $J_{\mathrm{i}}$ with complexation time at TMP of 1.0 bar and $\mathrm{pH}$ of 7.0. With increasing complexation time, $R_{\mathrm{Ni}}$ increases rapidly in the first $30 \mathrm{~min}$, and then

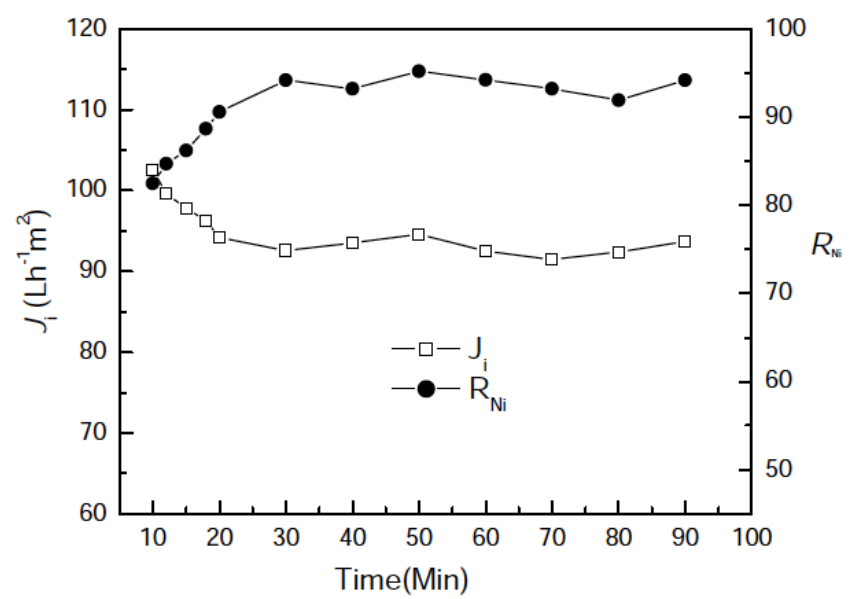

Figure 7: Effect of complexation time on permeate flux and retention rate (PVP concentration, 100mg/L; nickel concentration, $25 \mathrm{mg} / \mathrm{L} ; \mathrm{pH}, 7$; temperature, $25^{\circ} \mathrm{C}$; transmembrane pressure, 1.0 bar). 
keeps steady. Since nickel concentration in the permeate is considered to be equal to free nickel concentration in the retentate, $30 \mathrm{~min}$ is regarded as the minimum time for reaching complexation equilibrium. In addition, $J_{i}$ decreases slightly as the complexation time increases.

\subsubsection{Effect of Loading Ratio on Nickel Removal}

The loading ratio is one of the most important parameters for the CP-UF process [12-15]. The effect of loading ratio on $R_{\mathrm{Ni}}$ and $J_{\mathrm{s}}$ is shown Figure $8 . R_{\mathrm{Ni}}$ value increases with loading ratio in the range 1-4, and then remains unchanged when loading ratio is beyond 4. This is because the available sites of PVP increase with loading ratio. Similar trends were observed in other studies $[16,17] . J_{s}$ decreases slightly with loading ratio, which may be due to the increased viscosity of feed solution. As a result, the optimum loading ratio of 4 was chosen for further complexation-ultrafiltration process.

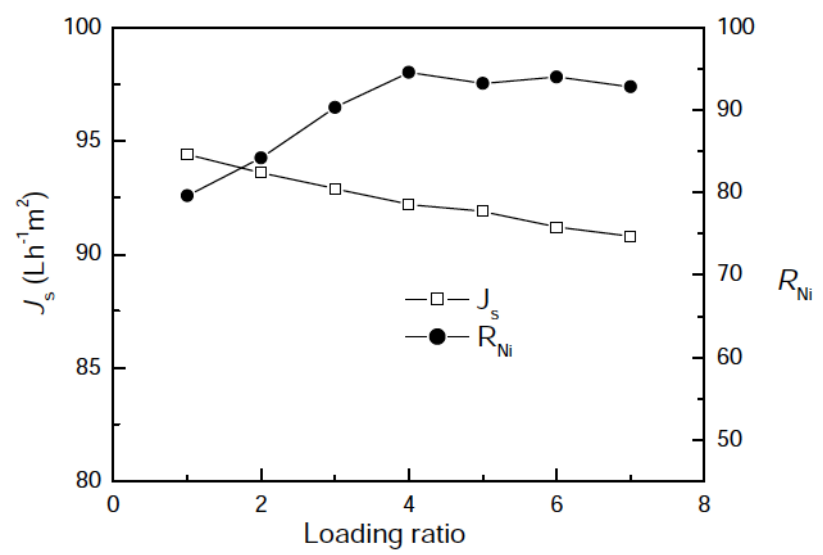

Figure 8: Effect of loading ratio on retention rate and steady permeate flux Js (nickel concentration, 25mg/L; $\mathrm{pH}, 7$; temperature, $25^{\circ} \mathrm{C}$; transmembrane pressure, $1.0 \mathrm{bar}$ ).

\subsubsection{Effect of $\mathrm{pH}$ on Nickel Removal}

In the process of CP-UF, $\mathrm{pH}$ value is another important parameter. Figure 9 shows the effect of $\mathrm{pH}$ on $R_{\mathrm{Ni}}$ and $J_{\mathrm{s}}$ at temperature of $25^{\circ} \mathrm{C}$ and TMP of 1.0 bar. $R_{\mathrm{Ni}}$ value increases from $79.6 \%$ to $95.7 \%$ as $\mathrm{pH}$ value increases from 3.0 to 10.0 . This phenomenon can be explained that, competition exists between $\mathrm{Ni}$ (II) and proton $\mathrm{H}^{+}$to bind PVP in complexation process. There is chemical equilibrium and reaction formula [9] between the ligand PVP (L), proton $\mathrm{H}^{+}$and $\mathrm{Ni}$ (II) in aqueous solution, as shown in reactions (a) and (b):

$$
\begin{aligned}
& \mathrm{L}+\mathrm{H}^{+} \rightleftharpoons \mathrm{LH}^{+} \\
& \mathrm{L}+\mathrm{Ni}(\mathrm{II}) \rightleftharpoons \mathrm{LNi}(\mathrm{II})
\end{aligned}
$$

At lower $\mathrm{pH}$, much more proton $\mathrm{H}^{+}$accelerates easily the formation of $\mathrm{LH}^{+}$in reaction (a) while it inhibits the formation of $\mathrm{LNi}(\mathrm{II})$. So, many nickel ions exist still in the free state and pass through the membrane. At higher $\mathrm{pH}$, owing to the lower concentration of $\mathrm{H}^{+}$, the formation of $\mathrm{LNi}(\mathrm{II})$ is easy in reaction (b). This makes that many nickel ions are bound to the PVP and rejected by the membrane. At neutral or basic $\mathrm{pH}$, high retention is attributed to partial hydrolysis of nickel ions, resulting in formation of $\mathrm{Ni}(\mathrm{OH})_{2}$ with minimum protonation and maximum deprotonation phenomenon, leading to the enhancement of metal retention [18]. So $\mathrm{pH}$ of 7 is much more suitable to obtain better $R_{N i}$. In addition, $J_{\mathrm{s}}$ decreases slightly as $\mathrm{pH}$ value increases from 3.0 to 10.0 .

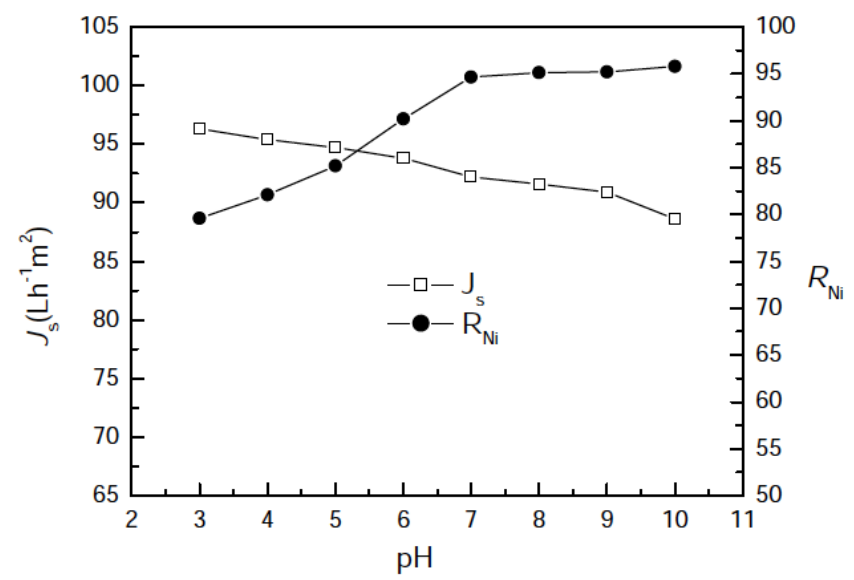

Figure 9: Effect of $\mathrm{pH}$ on retention rate and steady permeate flux (PVP concentration, $100 \mathrm{mg} / \mathrm{L}$; nickel concentration, 25 $\mathrm{mg} / \mathrm{L}$; temperature, $25^{\circ} \mathrm{C}$; transmembrane pressure, $1.0 \mathrm{bar}$ ).

\subsubsection{Effect of the Added Salt on Nickel Removal}

Since chloride ions exist largely in actual industrial wastewater, sodium chloride is used as a representative salt in this work. Figure 10 shows the effect of the concentration of the added salt (sodium chloride) on $R_{\mathrm{Ni}}$ and $J_{\mathrm{s}}$. Ultrafiltration experiments were conducted with the applied pressure of 1 bar, loading ratio of 4 and $\mathrm{pH}$ value of 7 . One can see that $R_{\mathrm{Ni}}$ value decreases with increasing the concentration of sodium chloride, and then changes little. One possible mechanism to explain the effect of background electrolytes on nickel removal is that increasing the salt concentration of the solution probably leads to compression of the electric double layer, thus to reduction in the binding between ions and polymer [16]. As a result, the unbound nickel in the solution passes through the membrane, leading to lower retentions. It is similar to what Baticle et al. [19] observed for $\mathrm{Ni}(\mathrm{II})$ removal by using polyethyleneimine as a complexing agent. In addition, $J_{\mathrm{s}}$ slightly decreases from 92.2 to 
87.6 $\mathrm{L} \mathrm{h}^{-1} \mathrm{~m}^{-2}$ as the concentration of sodium chloride increases from 2 to $12 \mathrm{mg} / \mathrm{L}$. It may be due to compression of the electric double layer which leads slight membrane fouling, thus there is a reduction of $J_{s}$.

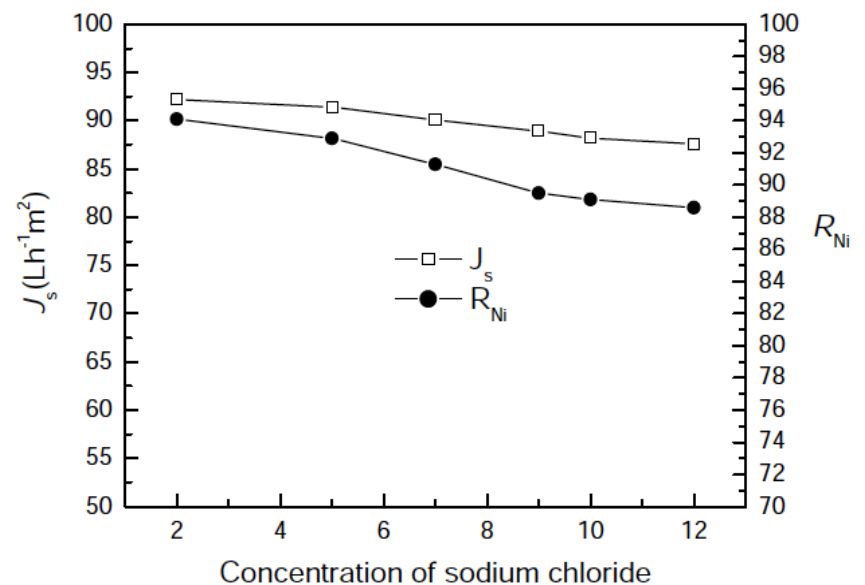

Figure 10: Effect of the concentration of sodium chloride on retention rate and membrane permeate flux (PVP concentration, $100 \mathrm{mg} / \mathrm{L}$; nickel concentration, $25 \mathrm{mg} / \mathrm{L} ; \mathrm{pH}$, 7.0; temperature, $25^{\circ} \mathrm{C}$; transmembrane pressure, 1.0 bar).

\subsubsection{Effect of Transmembrane Pressure on Nickel Removal}

Figure 11 shows the effect of TMP on $R_{\mathrm{Ni}}$ and $J_{\mathrm{s}} . R_{\mathrm{Ni}}$ almost does not vary with increasing the TMP. This is because the formation of PVP-Ni(II) is not influenced by the TMP. $J_{\mathrm{S}}$ rapidly increases from 83.6 to $126.6 \mathrm{~L} \mathrm{~h}^{-}$ ${ }^{1} \mathrm{~m}^{-2}$ as the TMP increases from 0.5 to 1.5 bar. This fact indicates that the effect of concentration polarization is slight. Aliane et al. [20] obtained similar results in the studies of removing $\mathrm{Cr}$ (III) from wastewaters by ultrafiltration with the help of polyethyleneimine.

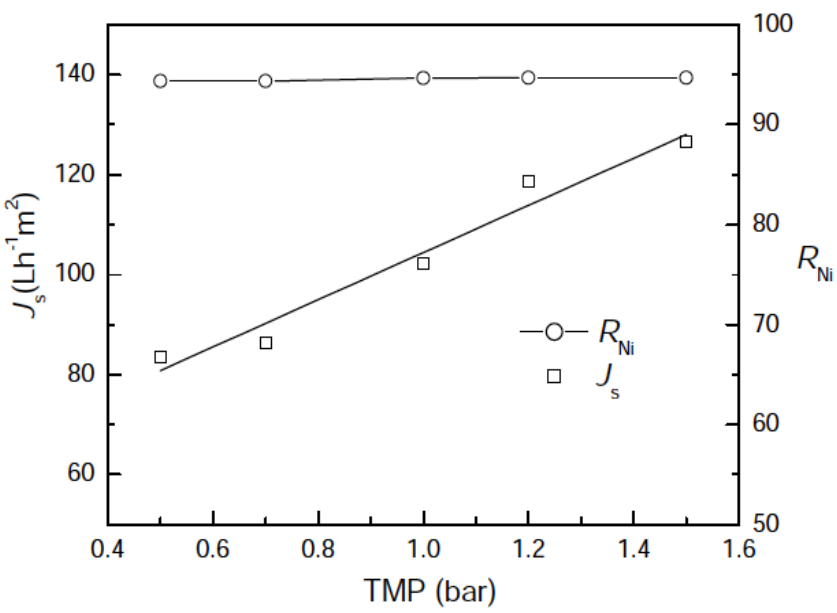

Figure 11: Effect of transmembrane pressure on retention rate and membrane permeate flux (PVP concentration, 100 $\mathrm{mg} / \mathrm{L}$; nickel concentration, $25 \mathrm{mg} / \mathrm{L} ; \mathrm{pH}, 7.0$; temperature, $\left.25^{\circ} \mathrm{C}\right)$.

\subsection{Concentration Process}

According to the results of the previous experiments, $\mathrm{pH}$ of 7 , TMP of 1.0 bar and loading ratio of 4 were selected for the concentration process. Figure 12 shows the effect of volume concentration factor (VCF) on nickel retention rate, membrane permeate flux, nickel concentrations in the retentate $\left(C_{\mathrm{r}}\right)$ and the permeate $\left(C_{\mathrm{p}}\right) . R_{\mathrm{Ni}}$ obtained at different VCF are very high (approximated to $93 \%$ ). Membrane permeate flux decreases from 97.3 to $88.6 \mathrm{~L} \mathrm{~h}^{-1} \mathrm{~m}^{-2}$ as the VCF increases from 1 to 10 , which can be attributed mainly to the insignificant concentration polarization. With increasing VCF, there is a rapid linear increase of $C_{r} . C_{r}$ is $192.3 \mathrm{mg} / \mathrm{L}$ when VCF reaches 10 . However, $C_{p}$ almost keeps a steady value and is approximately $1.5 \mathrm{mg} / \mathrm{L}$ in the whole concentration process. This implies that nickel is concentrated efficiently by the membrane under the conditions. A similar result has also been observed in our previous study [10].

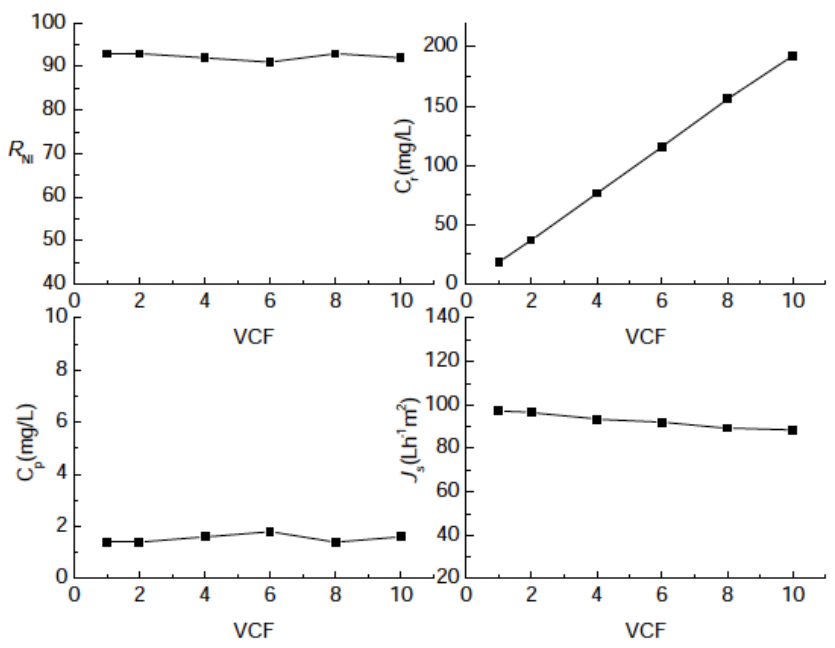

Figure 12: The effects of volume concentration factor on nickel retention rate, membrane permeate flux, nickel concentrations in the retentate and the permeate (feed volume, $10 \mathrm{~L}$; initial PVP concentration, $80 \mathrm{mg} / \mathrm{L}$; initial nickel concentration, $20 \mathrm{mg} / \mathrm{L} ; \mathrm{pH}, 7.0$; temperature, $25^{\circ} \mathrm{C}$; transmembrane pressure, $1.0 \mathrm{bar}$ ).

\subsection{Decomplexation Process}

$1 \mathrm{~L}$ concentrated solution was obtained which contains nickel and PVP concentrations of $192.3 \mathrm{mg} / \mathrm{L}$ and $742.5 \mathrm{mg} / \mathrm{L}$, respectively. The possibility of achieving the decomplexation of PVP-Ni(II) complexes was tested at $\mathrm{pH} 3$ in total recirculation mode. Once the decomplexation began, $C_{\mathrm{r}}$ and $C_{\mathrm{p}}$ were measured at intervals. Figure 13 shows the effect of decomplexation time on permeate flux, $C_{\mathrm{r}}$ and $C_{\mathrm{p}}$. It can be seen that 
permeate flux and $C_{\mathrm{r}}$ hardly change with decomplexation time. $C_{\mathrm{p}}$ increases with decomplexation time, and it changes little after about 15 minutes. Since nickel concentration in the permeate is considered to be equal to free nickel concentration in the retentate, 15 min is regarded as the minimum time for reaching decomplexation equilibrium. The equilibrium nickel concentrations in the retentate and the permeate are $192.3 \mathrm{mg} / \mathrm{L}$ and $80.7 \mathrm{mg} / \mathrm{L}$ respectively, which means that about $42 \%$ of PVP-Ni(II) complexes are dissociated. It demonstrates that some of nickel ions remain bound by the polymer.



Figure 13: Effect of decomplexation time on permeate flux and nickel concentrations in the retentate and the permeate solution (feed volume, $1 \mathrm{~L}$; $\mathrm{pH}, 3$; temperature, $25^{\circ} \mathrm{C}$; transmembrane pressure, 1.0 bar; initial nickel concentration, 192.3 mg/L; PVP concentration, 742.5 mg/L). recovery percentage of binding capacity is higher than $90 \%$.

\section{CONCLUSION}

The CP-UF process was successfully applied for removal of nickel from aqueous solutions. Ceramic membrane was used as the ultrafiltration membrane, while polyvinyl pyrrolidone was used as a water-soluble polymeric ligand. Summing up the results obtained, special attention should be paid to the strong influence of $\mathrm{pH}$ on complexation-ultrafiltration. By changing $\mathrm{pH}$ values, it is possible to carry out the separation of nickel(II) or to decompose nickel(II)-PVP complex. Nickel(II)-PVP complex can be concentrated effectively when the appropriate $\mathrm{pH}$ and loading rate (such as $\mathrm{pH}=7.0$ and $\mathrm{L}=4.0$ ) are selected. Nickel(II) is removed effectively from the retentate using the decomplexation, and the purification of regenerated PVP is acceptably satisfactory. The binding capacity of regenerated PVP is close to that of fresh PVP. Therefore, it is possible to carry out the recovery of nickel(II) and the reuse of PVP by the integration of experiments including complexation, concentration, decomplexation and regeneration.

\section{ACKNOWLEDGEMENTS}

This research is supported by the National Natural Science Foundation of China (No. 51573041). Also, the authors acknowledge the financial supports from the Key Research Foundation of Education Bureau of

Table 2: The Binding Capacities of the Regenerated and Fresh PVPs

\begin{tabular}{|c|c|c|c|c|c|c|c|}
\hline ratio $\boldsymbol{R}$ value & $\mathbf{1}$ & $\mathbf{2}$ & $\mathbf{3}$ & $\mathbf{4}$ & $\mathbf{5}$ & $\mathbf{6}$ & $\mathbf{7}$ \\
\hline \hline$R$ of fresh PVP & 79.6 & 84.2 & 90.3 & 94.56 & 94.53 & 94.61 & 94.52 \\
\hline$R$ of regenerated PVP & 72.6 & 77.4 & 83.5 & 86.1 & 86.7 & 87.0 & 87.1 \\
\hline
\end{tabular}

\subsection{Regeneration of Polymer}

After the decomplexation experiments, the retentate was treated by adding hydrochloric acid solution of $\mathrm{pH}=3$ and the regenerated PVP as pure as possible were tested by using the diafiltration method. Nickel should be progressively washed by passing the permeate, while PVP was retained in the retentate. After the previous diafiltration experiment, the regenerated PVP was used to bind nickel ions. As shown in Table 2, the binding capacity of the regenerated PVP is close to that of fresh PVP, and the
Hunan Province of China (No. 15A061) and the Demonstration Base Project of University-Enterprise Cooperation of Hunan Province of China (No. 145812).

\section{REFERENCES}

[1] Fu FL, Wang Q. Removal of heavy metal ions from wastewaters: a review. Journal of Environmental Management 2011; 92: 407-418. http://dx.doi.org/10.1016/j.jenvman.2010.11.011

[2] Mimoune S, Amrani F. Experimental study of metal ions removal from aqueous solutions by complexationultrafiltration. Journal of Membrane Science 2007; 298: 9298.

http://dx.doi.org/10.1016/j.memsci.2007.04.003 
[3] Cojocaru C, Zakrzewska-Trznadel G, Jaworska A. Removal of cobalt ions from aqueous solutions by polymer assisted ultrafiltration using experimental design approach, part1:Optimization of complexation conditions. Journal of Hazardous Materials 2009; 169: 599-609. http://dx.doi.org/10.1016/j.jhazmat.2009.03.145

[4] Zeng JX, Ye HQ, Hu ZY. Application of the hybrid complexation-ultrafiltration process for metal ion removal from aqueous solutions. Journal of Hazardous Materials 2009; 161: 1491-1498.

http://dx.doi.org/10.1016/j.jhazmat.2008.04.123

[5] Desai KR, Murthy ZVP. Removal of silver from aqueous solutions by complexation-ultrafiltration using anionic polyacrylamide. Chemical Engineering Journal 2012; 185186: 187-192. http://dx.doi.org/10.1016/j.cej.2012.01.072

[6] Barakat MA. New trends in removing heavy metals from industrial wastewater[J]. Arabian Journal of Chemistry 2011; 4(4): 361-377. http://dx.doi.org/10.1016/j.arabjc.2010.07.019

[7] Reck BK, Müller DB, Rostkowski K, Graedel TE. Anthropogenic nickel cycle: insights into use, trade, and recycling. Environmental Science and Technology 2008; 42: 3394-3400. http://dx.doi.org/ 10.1021/es072108I

[8] Denkhaus E, Salnikow K. Nickel essentiality, toxicity, and carcinogenicity. Critical Reviews in Oncology-Hematology 2002; 42: 35-56.

http://dx.doi.org/10.1016/S1040-8428(01)00214-1

[9] Qu YR, Mao LJ. Removal of heavy metal ions from aqueous solution by ultrafiltration assisted with copolymer of maleic acid and acrylic acid. Desalination 2013; 329: 78-85. http://dx.doi.org/10.1016/j.desal.2013.09.012

[10] Zeng JX, Sun XH. Recovery of Tungsten (VI) from Aqueous Solutions by Complexation-ultrafiltration Process with the Help of Polyquaternium. Chinese Journal of Chemical Engineering 2012; 20: 831-836. http://dx.doi.org/10.1016/S1004-9541(12)60406-6

[11] Khosa MA, Shah SS, Feng X. Metal sericin complexation and ultrafiltration of heavy metals from aqueous solution. Chemical Engineering Journal 2014; 244: 446-456. http://dx.doi.org/10.1016/j.cej.2014.01.091
[12] Ennigrou DJ, Gzara L, Ben Romdhane MR, Dhahbi M. Cadmium removal from aqueous solutions by polyelectrolyte enhanced ultrafiltration. Desalination 2009; 246: 363-369. http://dx.doi.org/10.1016/j.desal.2008.04.053

[13] Mimoune S, Belazzougui RE, Amrani F. Purification of aqueous solutions of metal ions by ultrafiltration. Desalination 2007; 217: 251-259.

http://dx.doi.org/10.1016/j.desal.2007.01.016

[14] Bodzek M, Korus I, Loska K. Application of hybrid complexation-ultrafiltration process for removal of metal ions from galvanic wastewater. Desalination 1999; 121: 117-121. http://dx.doi.org/10.1016/S0011-9164(99)00012-0

[15] Osipova EA, Sladkov VE, Kamenev Al, Shkinev VM, Geckeler KE. Determination of $\mathrm{Ag}(\mathrm{I}), \mathrm{Hg}(\mathrm{II}), \mathrm{Cu}(\mathrm{II}), \mathrm{Pb}(\mathrm{II})$, $\mathrm{Cd}(\mathrm{II})$ by stripping voltammetry in aqueous solutions using complexing polymers in conjunction with membrane filtration. Analytica Chimica Acta 2000; 404: 231-240. http://dx.doi.org/10.1016/S0003-2670(99)00713-8

[16] Shao J, Shu Q, Davidson J, Li W. Recovery of nickel from aqueous solutions by complexation-ultrafiltration process with sodium polyacrylate and polyethylenimine. Journal of Hazardous Materials 2013; 244: 472-477. http://dx.doi.org/10.1016/j.jhazmat.2012.10.070

[17] Trivunac K, Stevanovic S. Removal of heavy metal ions from water by complexation-assisted ultrafiltration. Chemosphere 2006; 64: 486-491. http://dx.doi.org/10.1016/j.chemosphere.2005.11.073

[18] Periasamy K, Namasivayam C. Removal of nickel(II) from aqueous solution and nickel plating industry wastewater using an agricultural waste: Peanut hulls. Waste Manage 1995; 15: 63-68. http://dx.doi.org/10.1016/0956-053X(94)00071-S

[19] Baticle $P$, Kiefer C, Lakhchaf $N$, Leclerc O, Persin $M$ Sarrazin J. Treatment of nickel containing industrial effluents with a hybrid process comprising of polymer complexationultrafiltration-elec-trolysis. Separation and Purification Technology 2000; 18: 195-207. http://dx.doi.org/10.1016/S1383-5866(99)00063-5

[20] Aliane A, Bounatiro N, Cherif AT, Akretche DE. Removal of chromium from aqueous solution by complexation ultrafiltration using a water-soluble macroligand. Water Research 2001; 35: 2320-2326.

http://dx.doi.org/10.1016/S0043-1354(00)00501-7 